\title{
Resistance Measurement of Laser Welded Dissimilar Al/Cu Joints
}

\author{
P. Schmalen and P. Plapper \\ University of Luxembourg, 6, rue Richard Coudenhove-Kalergie L-1359 Luxembourg
}

\begin{abstract}
Aluminum and Copper were joined using the laser-based braze-welding process. By avoiding the intermixture of both conductive materials, the formation of brittle intermetallic compounds is strongly reduced. This results in a tough, ductile connection with reduced electric resistance. This paper describes a method, which is based on the 4-wire method, to measure the resistance of the weld seam. The arrangement of the conductive electrodes directly on top and bottom of the weld seam significantly increases the accuracy of the measured resistances, thus offers a direct estimation of the intermetallic layer thickness. The electric measuring of the layer thickness is a non-destructive method, which assists in the reduction of the post-process effort (cross sections, pull tests, hardness measurements) and decreases the lead-time by reducing the time needed for the identification of suitable laser process parameters.
\end{abstract}

DOI: 10.2961/jlmn.2017.03.0003

Keywords: dissimilar, laser, braze-welding, $\mathrm{Al}, \mathrm{Cu}$, electric resistance, IMC

\section{Introduction}

The main challenges for the e-mobility are the development of electric power trains and battery systems. Both have been part of intense research in the last years. The battery research was placed e.g. as one of the major goals of the germane ministry of research BMBF [1].

The main requirements for the joining technologies of battery tabs are the robustness and reliability of the process in a harsh battery environment [2], as well as a low contact resistance [3]. Beside of ultrasonic and friction welding, notably laser welding processes were developed to join $\mathrm{Al}$ and $\mathrm{Cu}$ [4], [5], [6]. The authors in [3] compared spot, ultrasonic and laser welding techniques for battery cells and showed that the laser process provides the lowest contact resistance while maintaining the best mechanical performance. Furthermore, the laser offers the advantages of contact-less power delivery and adaptability to differing joint geometries.

Each battery package consists of several battery cells, whereas the electrodes of those cells were usually made of aluminum and copper. The thermal joining of $\mathrm{Al}$ and $\mathrm{Cu}$ causes the intermixture of both materials, whereas intermetallic compounds (IMC) are formed. The characteristics of the IMC, in particular the electrical resistance, differ significantly from the metallic base metals used. The hardness of IMC are increased, the ductility decreased [7].

In order to prevent a brittle joint with high resistance, the formation of IMC in the weld seam must be reduced to a minimum. On the other hand, a minimum of IMC is required in order to form a joint between both materials.

The braze-welding principle [4] is a modified laser welding process to join $\mathrm{Al}$ and $\mathrm{Cu}$ based on the keyhole welding principle. The formation of brittle IMC is minimized by reducing the intermixture of both metals. The aluminum sheet is positioned in overlap configuration on top of the copper sheet. The aluminum is liquefied by the introduced laser en- ergy while the copper remains in solid state. Thus, a minimized fusion zone between both materials is formed and the formation of IMC is limited.

The main relations of resistance, mechanical performance, IMC layer thickness and hardness for $\mathrm{Al} / \mathrm{Cu}$ joints in overlap configuration are shown in Fig.1. The evaluation of $\mathrm{Al}-\mathrm{Cu}$ welds were described in [8].

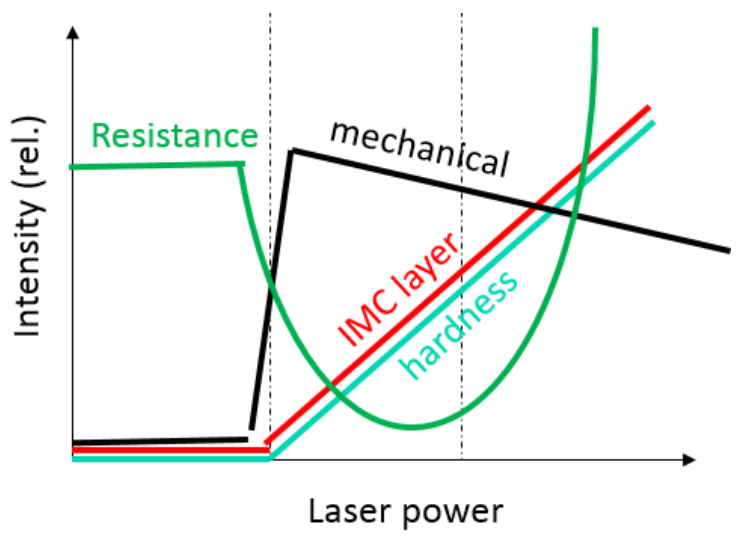

Fig. 1 Main relations between IMC layer thickness, mechanical properties hardness and resistance for laser-braze welded joints, as described in [8].

First, the laser power needs to be increased in order to be able to melt the upper $\mathrm{Al}$ sheet. The resistance is high. By increasing the energy input, the $\mathrm{Al}$ gets molten and will join to the $\mathrm{Cu}$. This is the second phase, the braze-welding phase, where the resistance reduces and the mechanical strength increases. By further increasing the energy input, more $\mathrm{Cu}$ will be molten and the intermixture will be increased. This leads to an augmented formation of IMC, resulting in a harder weld seam. The resistance increases again and the joint becomes brittle, the mechanical properties are reduced.

The challenge regarding the braze-welding process is the investigations of suitable process parameters, where a minimal IMC layer is achieved. Intensive post-process analysis 
in form of DoE needs to be performed. The motivation of this paper is the promotion of the process by reducing the lead time (less cross sections, pulls tests, samples).

By measuring the electrical resistance of the weld seam, the overall quality of the joint can be estimated. Furthermore, the mechanical performance and the electrical resistance can be optimized at the same time. The goal of this paper is the identification and description of how the IMC layer thickness can be determined based on electric resistance measurement.

\section{Electric resistance measurements}

The electric conductivity of aluminum and copper are among the highest of all metals. Comparably, the resistance is strongly reduced and requires precise measurement tools. The electric contact resistance of battery modules need to be reduced to a minimum in order to reduce losses by ohm's heating.

While measuring resistances of a few $\mathrm{m} \Omega$ and below, the resistance of the measurement wires cannot be neglected anymore. The 4-wire method is the most used method to measure resistances of one $\mu \Omega$ and below, e.g. the authors in [5], [6], [9] and [10] are using this method to measure the resistance of their joints. It is based on a separation of current delivering wires $C_{1} \& C_{2}$ and sensing wires $S_{1} \& S_{2}$, see fig 2 . Based on the higher current $\mathrm{i}$ inside the sample, a higher voltage drop on the weld seam is achieved, which is then precisely measured by the sensing wires. Since the sensing wires to no conduct the supply current, the serial resistance of the wires is strongly reduced compared to the weld seam resistance.

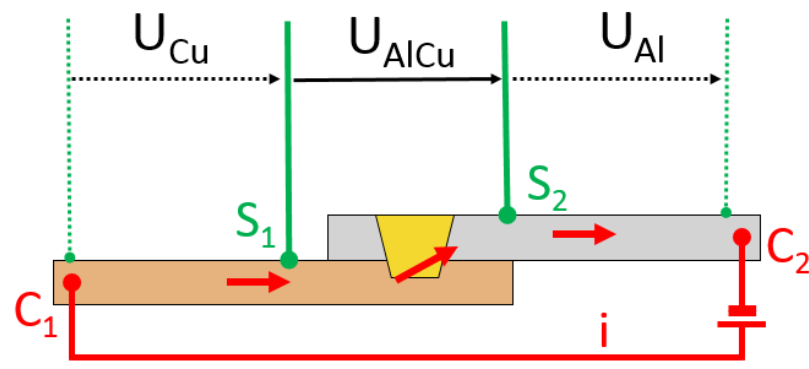

Fig. 2 4-wire method, shown on a welded specimen in overlap configuration. Two wires supply the current $\left(C_{1} \& C_{2}\right)$, the two other wires measure the Voltage $\left(\mathrm{S}_{1} \& \mathrm{~S}_{2}\right)$

The resistances measured by the 4-wire method are relative to the sample geometry, in order to make them comparable, the resistance equivalence factor $k_{U}$ is used [4], [5]:

$$
k_{U}=\frac{2 \cdot U_{A l C u}}{U_{C u}+U_{A l}}=\frac{2 \cdot R_{A l C u}}{R_{C u}+R_{A l}}
$$

The voltages $\mathrm{U}_{\mathrm{AlCu}}, \mathrm{U}_{\mathrm{Cu}}$ and $\mathrm{U}_{\mathrm{Al}}$ are measured by the sensing wires on the weld seam according to the positions fig. 2. Since the current $i$ is constant and known, the resistances $\mathrm{R}_{\mathrm{AlCu}}, \mathrm{R}_{\mathrm{Cu}}$ and $\mathrm{R}_{\mathrm{Al}}$ can be calculated aswell and result into the same factor $\mathrm{k}_{\mathrm{U}}$.

The resistance is the lowest for pure $\mathrm{Al}$ and $\mathrm{Cu}$, by intermixing both materials, intermetallic compounds are formed which increase the resistance. The authors in [11] give the resistivity $\rho$ for thin $\mathrm{Al} / \mathrm{Cu}$ films, measured at $200^{\circ} \mathrm{C}$. For pure $\mathrm{Al}$ and $\mathrm{Cu}$, the resistivity is lowest with 1.7-2.9 $\mu \Omega \mathrm{cm}$, for an alloy of $25 \% \mathrm{Al}$, the resistivity is $3-8$ times higher, between $8-14 \mu \Omega \mathrm{cm}$. Similar values have been used by [10]. The author in [12] states, that the resistivity ranges from 6.5 $\left(\mathrm{Al}_{2} \mathrm{Cu}\right)$ to $18.8\left(\mathrm{Al}_{4} \mathrm{Cu}_{9}\right) \mu \Omega \mathrm{cm}$. In [9], the author describes the thickness of the IMC layer $\mathrm{x}$ to be linear depended to the change in resistance $\Delta \mathrm{R}$ by $\Delta R=0.4 \cdot x[\%]$.

The author in [5] describes how the overall resistance of a weld seam can be reduced by changing the weld seam geometry, the connection between $\mathrm{Al}$ and $\mathrm{Cu}$ was realized by a platted interlayer in order to avoid the intermixture of $\mathrm{Al}$ and $\mathrm{Cu}$.

\section{Own approach}

The main challenge regarding the braze-welding of $\mathrm{Al} / \mathrm{Cu}$ is the reduction of intermixture of $\mathrm{Al}$ and $\mathrm{Cu}$ to avoid the formation of IMC. The braze-welding achieves this goal by minimizing the IMC layer thickness, thus results in best mechanical and electric joint properties.

In [10], the author states that the IMC layer is hard to measure by change in resistivity due to his small thickness of a few $\mu \mathrm{m}$. According to [4], the IMC layer thickness and therefore the joint performance is best beneath $10 \mu \mathrm{m}$. From [13] was shown, that the main transition from ductile to brittle break behavior for cold rolled Al-Cu joints occurs with an IMC layer thickness of $2.5 \mu \mathrm{m}$, which resulted in a relative resistance change of $4 \%$.

Regarding the 4-wire method, the weld seam consists of a serial connection of 3 resistances, one for each base material $R_{\mathrm{Cu}}$ and $\mathrm{R}_{\mathrm{Al}}$ and one for the weld seam $\mathrm{R}_{\mathrm{AlCu}}$, see fig. 3 .

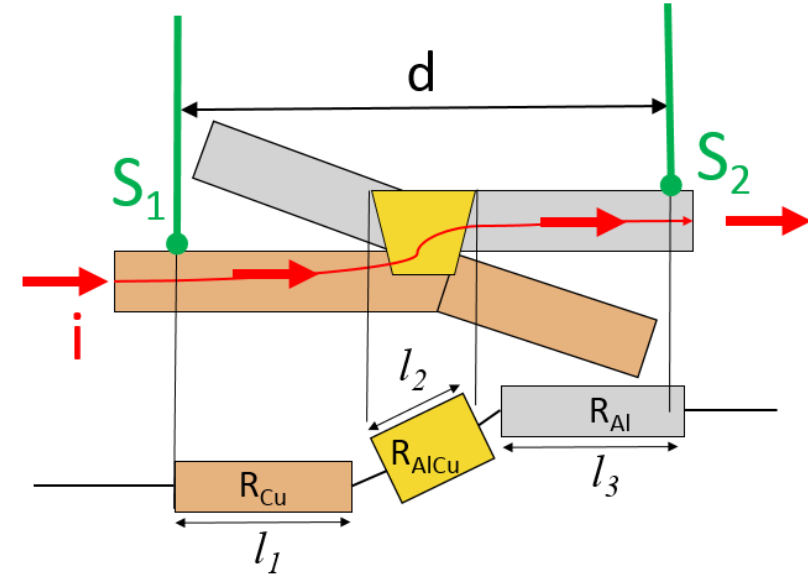

Fig. 3 Serial resistances of an overlap welded sample.

The resistance of the weld seam can be calculated by:

$$
R_{A l C u}=\rho_{I M C} \cdot \frac{l}{A}=\frac{l}{\sigma_{I M C} \cdot A}
$$

Where $\rho_{\text {IMC }}$ represents the notional resistivity of the weld seam, which consist of multiple intermetallic compounds. $\sigma_{\text {IMC }}$ is the respective conductivity of the weld seam. The length $d$ is the distance between the both sensing wires $S_{1}$ and $S_{2}$. The lengths $l_{1}$ and $l_{3}$ are the distances from the Sensing points to the weld seam. The distance $l_{2}$ represents the weld seam and is manly influenced by the process parameters.

The depth of the joint can be considered to be equal for the entire weld seam, thus the equation (2) can be adapted to: 


$$
R_{\text {spez }}=R_{\text {Cu }}+R_{\text {AlCu }}+R_{A l}=\frac{\rho_{C u} \cdot l_{1}+\rho_{I M C} \cdot l_{2}+\rho_{A l} \cdot l_{3}}{A}
$$

Whereby the overall distance $d=l_{1}+l_{2}+l_{3}$. The distance $d$ is always larger than the weld seam width, but should be minimal in order to decrease the impact of the serial resistance of the base materials. The distance $d$ is often not mentioned in publications, or chosen much larger than the weld seam width. If the distance $d$ is chosen much larger than $l_{2}$, the measured $\mathrm{R}_{\mathrm{AlCu}}$ consists mainly of $\mathrm{R}_{\mathrm{Cu}}$ and $\mathrm{R}_{\mathrm{Al}}$, see eq. 3 , and the $k_{u}$, see eq. 1 , is an inaccurate indicator for the joint quality.

Taking into account a change of IMC layer thickness from $1 \mu \mathrm{m}$ to $10 \mu \mathrm{m}$ and a symmetric distance $\mathrm{d}$ of $2 \mathrm{~mm}$ ( $\rho_{I M C}=4 \rho_{A l}=8 \rho_{C u}$, for estimation) and put those information in equation (3), the overall resistance change would be $+2 \%$. By increasing the distance $\mathrm{d}$ to $10 \mathrm{~mm}$, the resistance change would be $+0.3 \%$, thus challenging to measure.

The new approach seeks to minimize the serial resistances of the base materials by reducing the distance $\mathrm{d}$ between the measuring electrodes. Thus, the change of IMC layer thickness will yield in higher change of resistance. The electrodes were placed nearest to the IMC layer, on top and bottom of the weld seam, see fig 4 . The electrodes were chosen to have the diameter of the weld seam width $(1 \mathrm{~mm}$ in this case) to introduce the current flow directly into the weld seam. In order to measure the resistance of the weld seam, the electrodes were moving along the weld seam.

It should be noticed that according to eq. 3 the $\mathrm{R}_{\mathrm{AICu}}$ cannot be measured independent of $\mathrm{R}_{\mathrm{Al}}$ and $\mathrm{R}_{\mathrm{Cu}}$. The serial resistance of the electrode is minimized by increasing the diameter of the electrodes next to the weld seam.
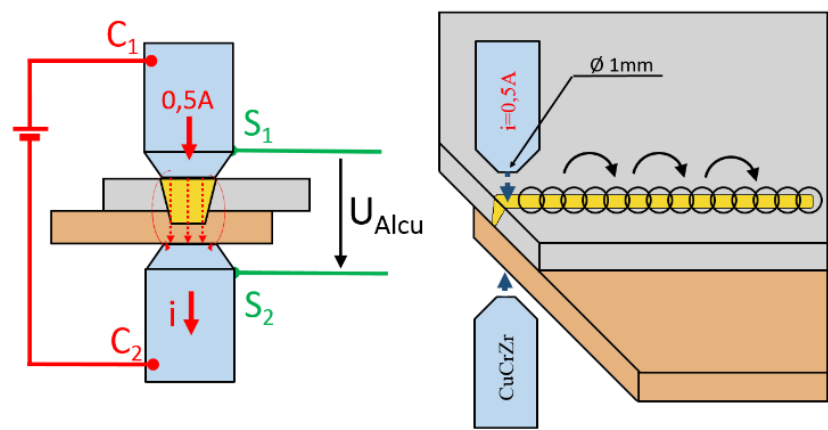

Fig. 4 setup for a sequential resistance measurement with electrodes on top and bottom of the weld seam.

This new setup offers three distinct advantages compared to the setup with the electrodes next to the weld seam:

- The serial resistances of the base material is reduced to a minimum

- It offers a sequential measurement of the resistance, thus enables the analysis of the formation of IMC along the weld seam.

- The diameter of the electrodes is adaptable to the weld seam width.

The electric measurement is a fast, nondestructive method to analyze the joint quality. It reduces the amount of post process analysis (hardness tests, cross sections and pull tests) significantly and therefore reduce the lead-time for the implementation of the laser-braze welding process.

\section{Experimental setup}

The welding experiments were carried out with a Trump TruDisk2000 and a 2D-Scanner optic, Trumpf PFO 20 $\left(\mathrm{f}_{\text {coll }}=90 \mathrm{~mm}, \mathrm{f}_{\text {foc }}=160 \mathrm{~mm}, \mathrm{~d}_{\text {spot }}=89 \mu \mathrm{m}, \lambda=1030 \mathrm{~nm}\right.$ ). The materials were purchased as band material with $40 \mathrm{~mm}$ width. The samples were cut with a puncher to a coupon size of $40 \times 45 \mathrm{~mm}$. The coupons need to be as flat and smooth as possible in order to avoid cracks and pores in the joint area. The samples were joined in overlap configuration, see fig 5 . They had an overlap of $10 \mathrm{~mm}$. The samples were fixed by toggle clamps.

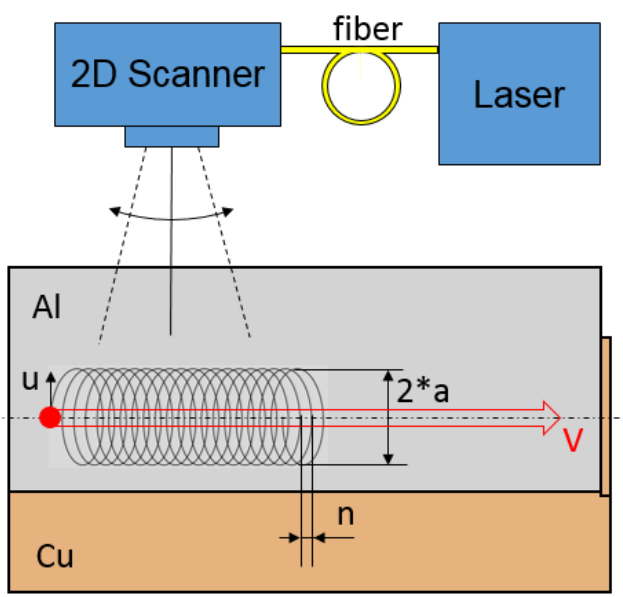

Fig. 5 top: The braze welding setup with $\mathrm{Al}$ on top of $\mathrm{Cu}$. Bottom: The spatial beam oscillation is used to adapt the weld width

The welding width was adapted using a spatial beam oscillation, the laser was used in cw-mode. Shielding gas has not been used. The cross sections were prepared by cold mounting the samples, grinding a polishing to 9,3 and $1 \mu$ diamond suspension. No etchant has been applied.

The electrodes were made of CuCrZr, a material also used for spot welding electrodes. The current was set to 0.5 A, preliminary experiments did not show any advantage of a higher current. The electrodes contact surface was $1 \mathrm{~mm}$ in diameter. The clamping force was $320 \mathrm{~N}$.

The data acquisition was performed with a Keithley Multimeter 2000. Each measurement consists out of 10 seperated measurements, whereas the average was saved. Before taking the measurements, the current was applied for 3 seconds.

In preparatory experiments, the influence of contact resistances was analyzed by comparing measurements with and without thermal compounds with high electric conductivity on the electrodes. No notable advantage was found, therefore the tests were performed without contact compound.

During the experiments, $0.6 \mathrm{~mm} \mathrm{Al} \mathrm{(99.5)} \mathrm{was} \mathrm{welded}$ to $0.6 \mathrm{~mm} \mathrm{Cu}$ (99.99) in order to calibrate the machine. Furthermore, $1 \mathrm{~mm} \mathrm{Al}$ was welded to $1 \mathrm{~mm} \mathrm{Cu}$ and $1.5 \mathrm{~mm} \mathrm{Al}$ to $0.4 \mathrm{~mm} \mathrm{Cu}$. The following parameters were used:

- $0.6 \mathrm{Al} / 0.6 \mathrm{Cu}, \mathrm{v}=200 \mathrm{~mm} / \mathrm{s}$ (without wobble)

- $\quad 0.6 \mathrm{Al} / 0.6 \mathrm{Cu}, \mathrm{a}=0.325, \mathrm{n}=0.2, \mathrm{u}=500 \mathrm{~mm} / \mathrm{s}$

- $1.0 \mathrm{Al} / 1.0 \mathrm{Cu}, \mathrm{a}=0.7, \mathrm{n}=0.4, \mathrm{u}=500 \mathrm{~mm} / \mathrm{s}$

- $1.5 \mathrm{Al} / 0.2 \mathrm{Cu}, \mathrm{v}=100 \mathrm{~mm} / \mathrm{s}$ (w/o wobble), 
Whereby the parameter $\mathrm{v}$ is the feeding rate of the laser beam on the weld seam. The forward movement was superposed by a wobble movement with an amplitude a (weld width $2 * a$ ) and an overlap $n$, which represents the actual shift for each circular movement of the laser spot with circular speed $u$.

The laser power was part of the experiments and is given in the result presentation. The wobble parameter and velocity were determined in preliminary experiments in order to achieve highest mechanical strength.

\section{Results}

The first results show the measured resistance of a $0.6 \mathrm{~mm} \mathrm{Al} / \mathrm{Cu}$ combination without wobble. For each power step, one sample was welded and measured 25 times along the weld seam. The results were presented as an array of boxplots. Three distinct process phases could be identified, see fig. 6 .

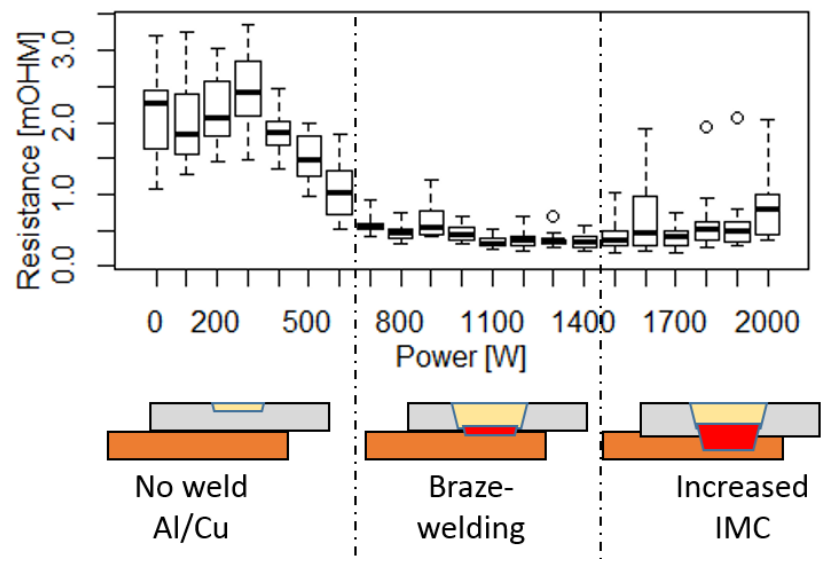

Fig. 6 welding of $0.6 \mathrm{~mm} \mathrm{Al} \mathrm{to} 0.6 \mathrm{~mm} \mathrm{Cu}$ without wobble. Three process phases were observed.

The resistance was highest for unwelded samples and samples, where the Al was molten, but did not contact the $\mathrm{Cu}$. This can be explained by the roughness of the base material; the contact is made by many micro-contacts [5].

By contacting, braze-welding the $\mathrm{Cu}$, the resistance decreased from $2 \mathrm{~m} \Omega$ to $0.5 \mathrm{~m} \Omega$. The resistance converted to a stable minimum.

By increasing the laser energy, more $\mathrm{Cu}$ was molten and the intermixture was increased. As a result, the IMC layer thickness increased, as well as the total resistance of the weld seam. The resistance increased by $60 \%$ from $0.5 \mathrm{~m} \Omega$ to $0.8 \mathrm{~m} \Omega$.

The described process phases were aswell observed while changing the process parameters on the same material. The process parameters need to be adapted e.g. for new materials, changing geometries or replaced laser sources. The second experiment will thus be performed with changed parameters.

In fig. 7, the weld was performed with a wobble movement in order to enlarge the weld seam width and increase the contact area. Here, the energy steps from 100-400 W were not presented in the chart, since no joint was formed.

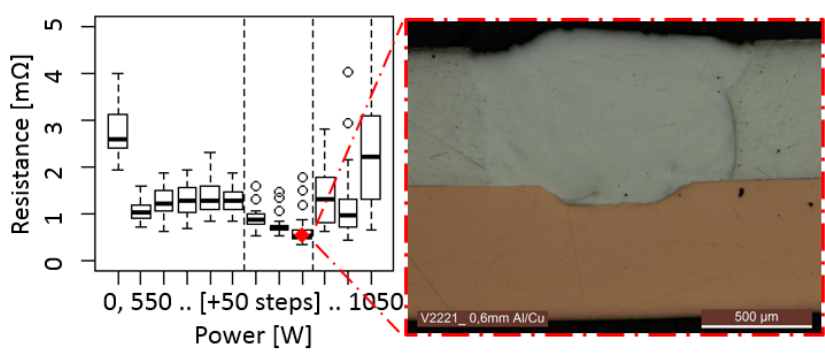

Fig. 7 Left: Resistance of $0.6 \mathrm{~mm} \mathrm{Al} \mathrm{to} 0.6 \mathrm{~mm} \mathrm{Cu}$ with wobble. Right: Cross section of the weld seam with lowest electric resistance.

The measured resistance was lowest for $900 \mathrm{~W}$, with a resistance of $0.52 \mathrm{~m} \Omega$. By increasing the energy, the resistance increased strongly compared to the previous experiment, which leads to the conclusion of increased intermixture caused by the wobble movement. In fig. 7 right, a cross section of the weld seam with lowest resistance is shown; the IMC layer thickness is strongly reduced, but sufficient for a strong mechanical connection.

Next, a thicker, $1 \mathrm{~mm} \mathrm{Al}$ to $1 \mathrm{~mm} \mathrm{Cu}$ combination, see fig. 8, was welded. The laser energy from 100-1000 Watt is not represented, no joint was formed.

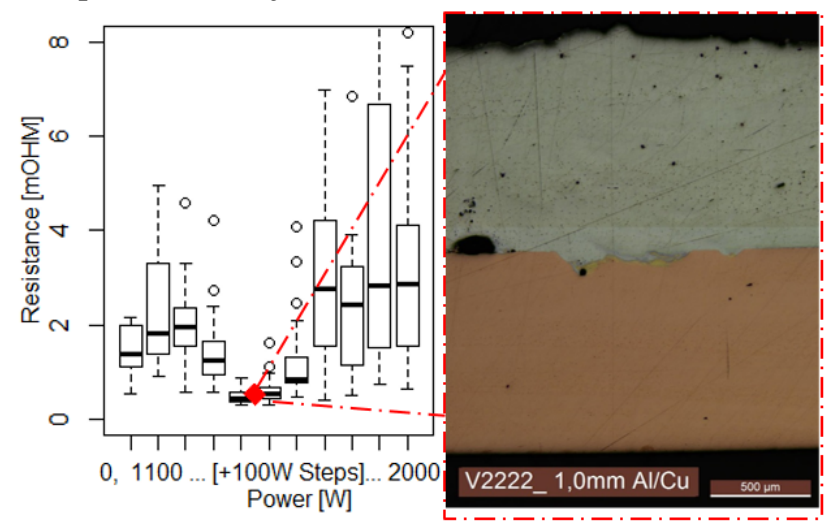

Fig. 8 Left: Resistance of $1 \mathrm{~mm} \mathrm{Al} \mathrm{to} 1 \mathrm{~mm} \mathrm{Cu}$ with wobble. Right: Cross section of the weld seam at $1450 \mathrm{~W}$

The measured resistances show again a declining resistance, until the braze-weld is fully developed. The minimal resistance was $0.49 \mathrm{~m} \Omega$. Then, the resistance increases up to $4 \mathrm{~m} \Omega$, which indicates a strong formation on IMC. The crosssection was made at $1450 \mathrm{~W}$, see fig 8 . The intermixture is minimal, and the IMC layer thickness significantly reduced.

All previous results were based on a series of sample, each sample was welded with a defined process parameter. The $1.5 \mathrm{~mm} \mathrm{Al}$ welded on $0.4 \mathrm{~mm} \mathrm{Cu}$, the laser power has been linearly increased from 0 to $2000 \mathrm{~W}$, see fig 9 . The weld was performed without wobble.

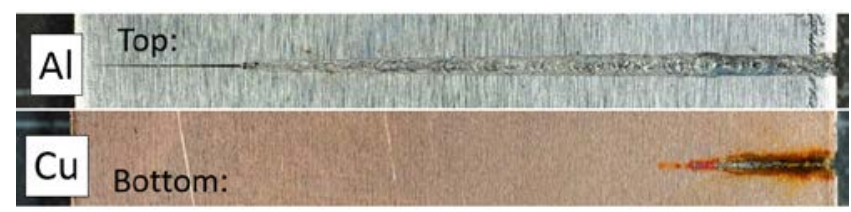

Fig. $91.5 \mathrm{~mm} \mathrm{Al}$ welded on $0.4 \mathrm{~mm} \mathrm{Cu}$ with increasing power, the same sample is shown from top and bottom side. 
The power ramp is clearly visible in fig.9. The resistance measurements have been taken along the weld seam, a total of 50 measurements were taken for each of 4 samples, see fig 10. A total of 4 samples were taken in order to check the repeatability of the measurement

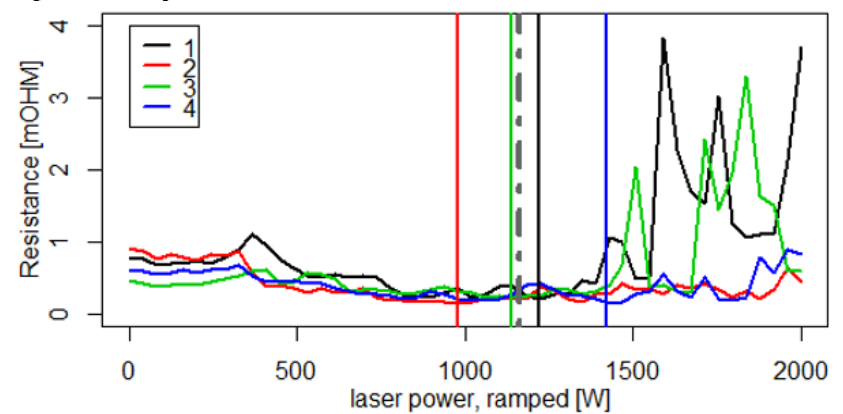

Fig. 10 The resistance measurement along the powerramped weld seam. Four samples were measured in total. The vertical lines indicate the minimal resistances.

It was confirmed that the resistance is high for unconnected $\mathrm{Al} / \mathrm{Cu}$, decreases from $400 \mathrm{~W}$ to $1100 \mathrm{~W}$ and then Increases again with more energy input. The respective minimum of each sample are:

$$
\begin{array}{ll}
\text { - } & 0.15 \mathrm{~m} \Omega \text { at } 980 \mathrm{~W} \\
\text { - } & 0.23 \mathrm{~m} \Omega \text { at } 1140 \mathrm{~W} \\
\text { - } & 0.21 \mathrm{~m} \Omega \text { at } 1120 \mathrm{~W} \\
& 0.23 \mathrm{~m} \Omega \text { at } 1420 \mathrm{~W}
\end{array}
$$

The minimum resistance is found to be located between those measured minimal resistances, thus a series of three cross sections is prepared, see fig 11.

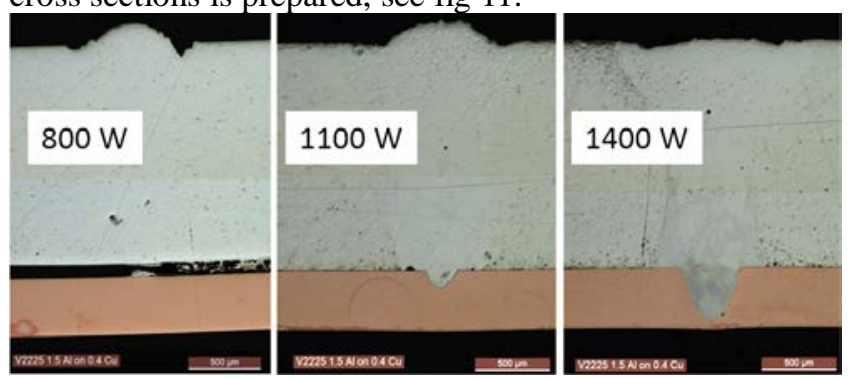

Fig. 11 Cross sections for the $1.5 \mathrm{Al}$ welded to $0.4 \mathrm{Cu}$, with unwelded, braze-welded and increased IMC weld seam

The cross sections correlate with the measured resistances. At $800 \mathrm{~W}$, the weld seam was not developed yet, the resistance was higher. At $1100 \mathrm{~W}$, the $\mathrm{Al}$ was contacted clearly with the $\mathrm{Cu}$. At $1400 \mathrm{~W}$, IMC were found (darkgrey and orange in color).

\section{Discussion}

It was found, that the resistance of unwelded material is always higher than the braze-welded joints. In average, the resistance for unwelded material is 3-5 times higher. The resistance of the overwelded samples is increased too, but not constantly. The samples welded without wobble had a slow increase of resistance, whereat the samples welded with wobble had a strong increase of the resistance. The reason therefore is an increased intermixture of material, which results in more IMC, see fig 1 . The increase of resistance is about 3-8 times higher and according to the literature similar to the theoretic resistivity of the IMC. A higher increase of the resistance could indicate the formation of IMC with higher resistivity, like $\mathrm{Al}_{4} \mathrm{Cu}_{9}$.

By using formula (3) and $\rho_{\mathrm{Cu}}=17 \mu \Omega \mathrm{cm}$, $\rho_{\mathrm{Al}}=28 \cdot \mu \Omega \mathrm{cm}$ from [12], the calculated resistance for a stackup of $1 \mathrm{~mm} \mathrm{Al}$ on $1 \mathrm{~mm} \mathrm{Cu}$ is for $\mathrm{R}_{\mathrm{Al}} 36 \mu \Omega$ and for $\mathrm{R}_{\mathrm{Cu}} 21 \mu \Omega$. For a braze weld, the $\mathrm{R}_{\mathrm{IMC}}$ is ideally 0 . The total resistance (excluding contact and electrode resistances) is then $49 \mu \Omega$. This resistance is about 3 times lower than the measured resistance for the power ramped experiment and about 10 times lower than the resistance for the other experiments. This deviation can be explained by contact and electrode resistances, or, as in case of the power ramped experiment, multiple measurements of the same position and thus compressing of the joint. Further investigations need to be carried out.

It was noticed, that there were significant higher resistances outliers for overwelded specimen, which could not only be explained by the presence of IMC with higher resistivity. These weld seams were found to be brittle, therefore cracks or/and pores were responsible for the outliers. Furthermore, it was noticed that the surface roughness was increased, which resulted in a corrupted contact resistance.

In the last experiment, the power ramped sample proved, that the best parameters for a minimal resistance are widespread. The reason therefore are on the one side the inaccuracy of the resistance measurements, but on the other side, it is known that the laser process itself relies on a dynamic keyhole process. As a result, each sample has already a given variance on his own.

The described method to estimate the thickness of the IMC layer thickness relies on precise measurements of the resistance. The results delivered possible parameters for braze-welding of $\mathrm{Al} / \mathrm{Cu}$ joints, but were not precise enough for a direct calculation of the thickness. A minimal resistance was found with the device, which gives assistance tool to predefine the process window, the refinement can be done by further post-processing.

\section{Conclusions}

The thickness of the intermetallic layer is crucial for the properties of the dissimilar joint. This paper describes a setup to estimate the thickness of the IMC layer by measuring the resistance of the weld seam. The 4-wire method has been used to perform those measurements. The main conclusions from this work are:

o The performance of dissimilar Al-Cu connectors depends directly on the thickness of the IMC layer.

o It was shown that the minimum resistance correlates with a minimum of IMC layer thickness.

o The minimum resistance of a weld seam was measured by placing the electrodes direct on top and bottom of the weld seam, thus reducing serial resistances.

o The described device can be used to predefine parameters for braze-welding, thus reducing the experimental effort need for each new material combination. 


\section{Acknowledgment}

This work is supported by the Fonds National de la Recherche (FNR) in Luxembourg under grant no. AFR 10155468.

\section{References}

[1] U. Deffke, U.: "Electric mobility—rethinking the car." (BMBF), (2013). From http://www.bmbf.de/pub/electric mobility rethinking the car.pdf, on 21.09.17.

[2] S. S. Lee, T.H. Kim, S.J. Hu, W. W. Cai and J. A. Abell: ASME 2010 int. manufacturing science and engineering conf., Erie, PA. (2010) p.541

[3] M.J. Brand, P.A. Schmidt, M.F. Zaeh, and A. Jossen: J. of Energy Storage, 1, (2015) 7

[4] T. Solchenbach and P. Plapper: Proc. of the COMA, 13, Stellenbosch, (2013). p.131

[5] P.A. Schmidt: Laserstrahlschweißen elektrischer Kontakte von Lithium-Ionen-Batterien in Elektro-und Hybridfahrzeugen (Vol. 304). Herbert Utz Verlag. (2015).

[6] A. Leitz: Laserstrahlschweißen von Kupfer-und Aluminiumwerkstoffen in Mischverbindung (Vol. 80). Herbert Utz Verlag. (2016).

[7] T.A. Mai, and A.C. Spowage: Materials Science and Engineering: A, 374, (2004) 224

[8] P. Schmalen and P. Plapper: Physics Procedia, 83, (2016), 506

[9] M. Braunovic and N. Aleksandrov: Electrical Contacts, Proc. of the Thirty-Ninth IEEE Holm Conf. on IEEE. (1993), p.261

[10]I. Bhamji, R.J. Moat, M. Preuss, P.L. Threadgill, A.C. Addison and M.J. Peel: Science and Tech. of welding and joining, 17, (2012), 314

[11]F. d'Heurle, C. Alliota, J. Angilello, V. Brusic, J. Dempsey and D. Irmischer : 2.22 Vacuum, 27, (1977), 321

[12] S. Pfeifer, S. Großmann, R. Freudenberger, H. Willing and H. Kappl: Electrical Contacts (Holm), IEEE 58th Holm Conf. on IEEE. (2012), p.1

[13] M. Abbasi, A.K. Taheri, and M.T. Salehi: J. of Alloys and Compounds, 319, (2001), 233

(Received: June 3, 2017, Accepted: September 30, 2017) 